\title{
Cord Blood Alkaline Phosphatase and Albumin as Probable Predictors of Significant Neonatal Jaundice in Healthy Full-Term Infants
}

\author{
Ahmed Thabet Mahmoud ${ }^{1}$, Seham Ahmed Khodeer ${ }^{2}$, Hanan Mostafa El-Sayed ${ }^{1}$, Youstina Isaac Zaki ${ }^{* 1}$ \\ Departments of ${ }^{1}$ Pediatrics and ${ }^{2}$ Clinical Pathology, Faculty of Medicine - Menoufia University \\ *Corresponding author: Youstina Isaac Zaki, Mobile: (+20) 1226454419, E-Mail: drminaezat@ hotmail.com
}

\begin{abstract}
Background: Hyperbilirubinemia in a neonate may occur in $60-70 \%$ of term and $80 \%$ of preterm babies. It is known to be associated with significant morbidity like neonatal bilirubin encephalopathy and even death. The concept of prediction of jaundice offers an attractive option to pick up babies at risk of neonatal hyperbilirubinemia.

Objective: To assess the predictive value of cord blood alkaline phosphatase (ALP) and cord albumin in development of indirect neonatal hyperbilirubinemia in healthy term infants.

Patients and method: This prospective cohort study was conducted at Obstetrics Emergency Department, Menoufia University Hospital and included (100) healthy full-term neonates over a period November 2019 to August 2020.

Result: The cord alkaline phosphatase in no jaundice group was $(248.63 \pm 71.73 \mathrm{U} / \mathrm{L})$ while in jaundice group it was significantly higher $(374.98 \pm 67.15 \mathrm{U} / \mathrm{L}, \mathrm{p}<0.01)$. The cord albumin in no jaundice group was $(3.72 \pm 0.18 \mathrm{~g} / \mathrm{dl})$ and in jaundice group it was $(2.81 \pm 0.31 \mathrm{~g} / \mathrm{dl})$ with a highly significant decrease in jaundice group than the no jaundice group ( $\mathrm{p}<0.01$ ). The area under the curve was 0.965 , at the cutoff value of alkaline phosphatase more than $315(\mathrm{U} / \mathrm{L})$, with a sensitivity of diagnosis of jaundice $95.0 \%$, and a specificity $100.0 \%$. Also, the area under the curve was 0.983 at the cutoff value of cord albumin $(\mathrm{g} / \mathrm{dl})$ less than $2.82(\mathrm{~g} / \mathrm{dl})$ with sensitivity of diagnosis of jaundice $96.0 \%$ and a specificity of $100 \%$.

Conclusion: It can be concluded that both cord albumin levels and cord blood alkaline phosphatase in a healthy term neonate can predict the possibility of the neonate who will develop hyperbilirubinemia with a high sensitivity and specificity, with cutoff value less than $2.8 \mathrm{gm} / \mathrm{dl}$ for cord albumin and more than $315 \mathrm{U} / \mathrm{L}$ for alkaline phosphatase. Hence routine determination of cord albumin along with alkaline phosphatase can be implemented to keep track of at-risk neonates.
\end{abstract}

Keywords: Cord Albumin, Cord Blood Alkaline Phosphatase, Neonatal Hyperbilirubinemia.

\section{INTRODUCTION}

Hyperbilirubinemia in a neonate may occur in $60-70 \%$ of term and $80 \%$ of preterm babies. It is known to be associated with significant morbidity like neonatal bilirubin encephalopathy and even death ${ }^{(\mathbf{1})}$. Early discharge of healthy term newborns after delivery has become a common practice because of medical and social reasons and economic constraints. It is significant that most common cause for readmission during the early neonatal period is hyperbilirubinemia ${ }^{(2)}$.

American Academy of Pediatrics recommends that neonate discharged within 48 hours should have a follow-up visit after 48 to 72 hours for any significant jaundice and any other problems ${ }^{(3)}$. Kernicterus occurs in more than $50 \%$ of infants with total bilirubin levels $>30 \mathrm{mg} / \mathrm{dL}$ but rarely occurs at levels $<20$ $\mathrm{mg} / \mathrm{dL}$. Infants with total bilirubin levels $>35 \mathrm{mg} / \mathrm{dL}$, regardless of etiology or rapidity of intervention, were observed to achieve some degree of irreversible sequelae ${ }^{(4)}$.

The concept of prediction of jaundice offers an attractive option to pick up babies at risk of neonatal hyperbilirubinemia. Since physical examination is not a reliable measure of the estimation of serum bilirubin; under these circumstances it would be desirable to be able to predict the risk of significant jaundice, in order to implement early treatment and thereby minimize the risk of bilirubin dependent brain damage ${ }^{(5)}$.

Early detection of risk factors is the first step towards prevention of hyperbilirubinemia and a step ahead in protecting newborns from complications at later age. There are few references which predict postnatal hyperbilirubinemia by estimating cord blood bilirubin levels but vary in opinions. Usually, albumin binds with unconjugated bilirubin and protects against kernicterus. Blood albumin in neonates is mostly derived from maternal circulation till baby's liver starts synthesis. There is paucity of reports on cord blood albumin level as a predictor of hyperbilirubinemia ${ }^{(6)}$.

Alkaline phosphatase (AP) level was used 6 hours after birth as a marker for determining hemolysis and hyperbilirubinemia ${ }^{(7)}$.

Measurement of cord blood AP may be a predicting marker for neonatal jaundice that necessitates treatment in the first week of life either with phototherapy or exchange transfusion ${ }^{(8)}$.

The aim of this study was to assess the predictive value of cord blood alkaline phosphatase and cord albumin in development of indirect neonatal hyperbilirubinemia in healthy term infants. 


\section{PATIENTS AND METHOD}

Study Design: This prospective cohort study was conducted at Obstetrics Emergency Department, Menoufia University Hospitals and included (100) healthy full-term neonates over a period November 2019 till August 2020.

\section{Ethical Approval:}

All procedures were carried out in accordance with the ethical standards of the institutional committee and with the 1964 Declaration of Helsinki. The study received the approval of Ethical Committee of Faculty of Medicine, Menoufia University. The aim and steps of the study were explained to all parents and written informed consent were obtained from them.

\section{Inclusion criteria:}

Healthy newborn infants. Gestational age between 37 and 42 weeks. Weight more than 2500 g. Both sexes. Apgar score of more than 7 at first and fifth minute of life.

\section{Exclusion criteria:}

Infants born to mothers diagnosed with eclampsia, diabetes, bone, kidney and liver diseases. Infants with any evidence of congenital or acquired diseases.

\section{Patient Preparation:}

\section{All the patients underwent:}

History taking which included: Personal history: Maternal age, consanguinity, maternal medical disorders during pregnancy and maternal medications, maternal blood group and $\mathrm{Rh}$, number of siblings (living, died) and if previous siblings had significant neonatal hyperbilirubinemia.

Natal history: Multiple pregnancy, mode of delivery, resuscitation data, Apgar score at 1 and $5 \mathrm{~min}$.

Examination: General examination and vital signs. Anthropometric measurements, Assessment of gestational age by Ballard score plus detailed chest, heart, abdominal and neurological examination

Therapeutic modalities: Phototherapy or exchange transfusion when indicated and use of intravenous immunoglobulin (IVIG) when needed.

\section{Laboratory investigations:}

In the delivery room, clamping the umbilical cord by 2 clamps, placed 4 to 6 inches apart and 3-5 $\mathrm{ml}$ of cord venous blood to be drained by sterile syringe into a specimen tube. The following are to be assessed: Cord serum alkaline phosphatase level by using Kinetic, photometric, optimized DCGK method, Cord serum albumin level by using bromocresol green method (BCG), Total and direct bilirubin by colorimetric method, Cord hemoglobin percent using cell counter T 660, Cord reticulocyte count examined manually after staining with brilliances blue under oil emersion lens. Blood groups (ABO, Rh) were determined for newborns and mothers, follow up of serum bilirubin was done on days one, three and five of life for all newborns and daily for admitted newborns until discharge. Significant indirect neonatal hyperbilirubinemia is considered according to American Academy of Pediatrics Clinical Practice Guidelines in neonates who developed neonatal hyperbilirubinemia needing intervention in the form of phototherapy and/or exchange transfusion ${ }^{(9)}$.

\section{Included newborn were grouped into:}

Group I: included 56 non-jaundice subjects (21 males and 35 females).

Group II: included 44 jaundice patients (21 males and 23 females).

\section{Statistical analysis}

The data collected were tabulated and analyzed by SPSS version 25 on IBM compatible computer. Quantitative data were expressed as mean and standard deviation (SD) and analyzed by applying student t-test. Qualitative data were expressed as number and percentage (No and \%) and compared by Chi square test or Fisher exact test. ROC curve and Pearson correlation were used. $\mathrm{p}<0.05$ was considered a statistically significant level.

\section{RESULTS}

In the current study, there was no significant difference between the two groups regarding demographic and basic clinical data (Table 1). Also, $10.7 \%$ of mothers of no jaundice group had maternal medication, while in jaundice group $22.7 \%$ of the mothers had maternal medication. 
Table (1): Comparison between the two groups regarding demographic and basic clinical data

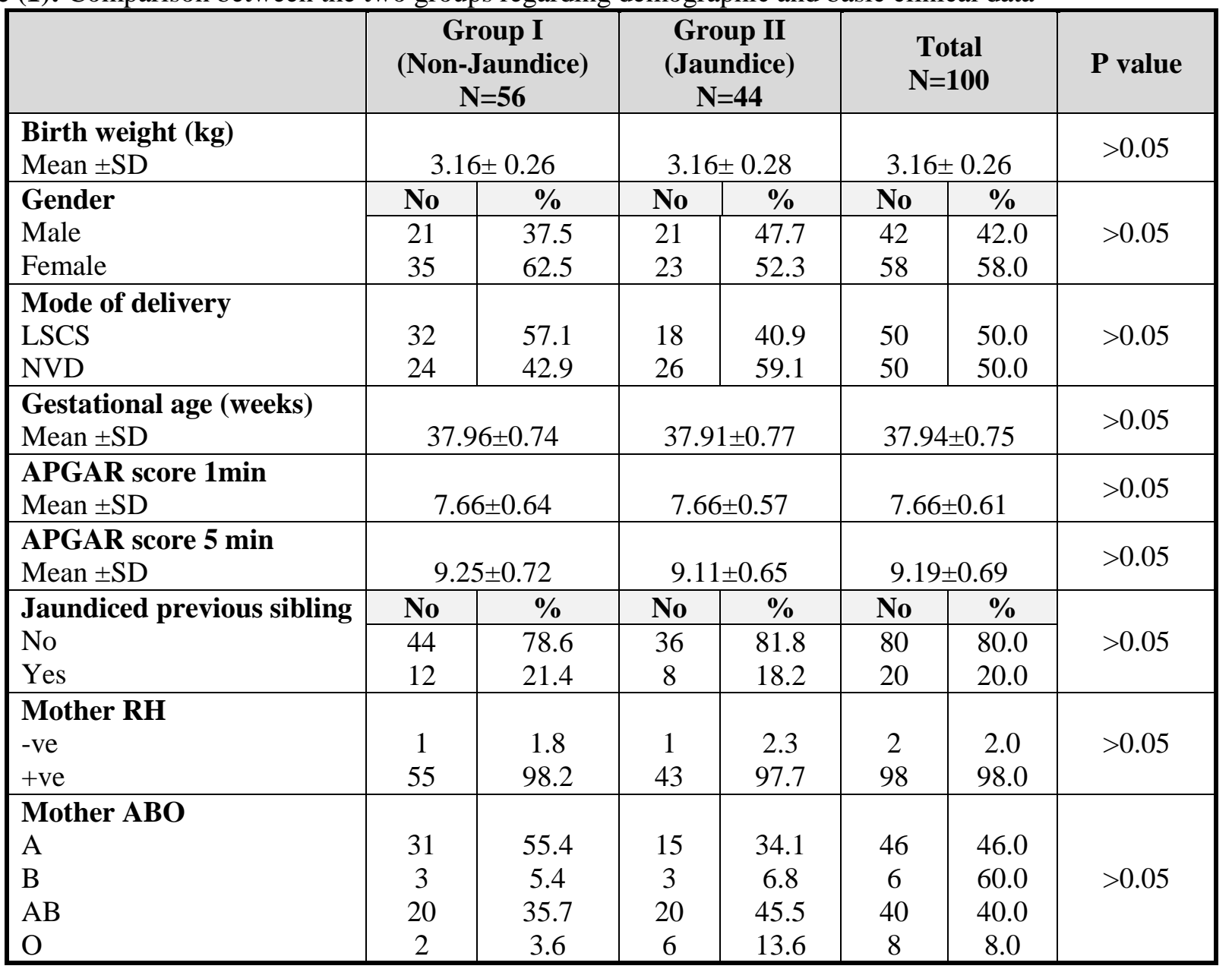

The reticulocytes were significantly more in jaundice group than no jaundice group. The cord alkaline phosphatase in jaundice group was significantly higher. The cord albumin showed a highly significant decrease in jaundice group than the no jaundice group. The total bilirubin at day 1 showed a significant increase in jaundice more than non-jaundice, at $3^{\text {rd }}$ and $5^{\text {th }}$ day the level of total bilirubin was still significantly higher in jaundice group than no jaundice. The level of direct bilirubin at $3^{\text {rd }}$ and $5^{\text {th }}$ day was significantly higher in jaundice group than no jaundice group (Table 2).

Table (2): Comparison between the two studied groups regarding cord alkaline phosphatase, cord albumin total and direct bilirubin at different period of follow up

\begin{tabular}{|c|c|c|c|c|c|}
\hline & & $\begin{array}{c}\text { Group I } \\
\mathbf{N}=\mathbf{5 6})\end{array}$ & Group II (N=44) & Total (N=100) & $\begin{array}{c}\text { P } \\
\text { value }\end{array}$ \\
\hline Hb (mg/dl) & Mean \pm SD & $15.36 \pm 0.93$ & $15.71 \pm 0.86$ & $15.51 \pm 0.91$ & $>0.05$ \\
\hline RETICS & Mean \pm SD & $2.08 \pm 0.83$ & $2.64 \pm 0.14$ & $2.33 \pm 0.01$ & 0.006 \\
\hline I/T ratio & Mean \pm SD & $0.0633 \pm 0.030$ & $0.0771 \pm 0.057$ & $0.075 \pm 0.544$ & $>0.05$ \\
\hline $\begin{array}{c}\text { Cord alkaline } \\
\text { phosphatase (U/L) }\end{array}$ & Mean \pm SD & $248.63 \pm 7.73$ & $374.98 \pm 7.15$ & $304.23 \pm 9.76$ & 0.001 \\
\hline Cord albumin (g/dl) & Mean \pm SD & $3.72 \pm 0.18$ & $2.81 \pm 0.31$ & $3.32 \pm 0.51$ & $<0.001$ \\
\hline Day 1 & & & & & \\
\hline T. bilirubin $(\boldsymbol{\mu m o l} / \mathbf{L})$ & Mean \pm SD & $3.41 \pm 0.81$ & $5.90 \pm 1.69$ & $4.51 \pm 1.07$ & 0.001 \\
\hline D. bilirubin( $\boldsymbol{\mu m o l} / \mathbf{L})$ & Mean \pm SD & $0.42 \pm 0.18$ & $0.40 \pm 0.17$ & $0.41 \pm 0.18$ & $>0.05$ \\
\hline Day 3 & & & & & \\
\hline T. bilirubin $(\boldsymbol{\mu m o l} / \mathbf{L})$ & Mean \pm SD & $4.96 \pm 1.22$ & $12.06 \pm 2.14$ & $8.08 \pm 1.92$ & $<0.001$ \\
\hline D. bilirubin( $\boldsymbol{\mu m o l} / \mathbf{L})$ & Mean \pm SD & $0.48 \pm 0.14$ & $0.63 \pm 0.14$ & $0.54 \pm 0.16$ & 0.001 \\
\hline Day 5 & & & & & \\
\hline T. bilirubin $(\boldsymbol{\mu m o l} / \mathbf{L})$ & Mean \pm SD & $4.52 \pm 1.14$ & $16.65 \pm 3.76$ & $9.65 \pm 2.55$ & $<0.001$ \\
\hline D. bilirubin $(\boldsymbol{\mu m o l} / \mathbf{L})$ & Mean $\pm S D$ & $0.41 \pm 0.18$ & $0.74 \pm 0.19$ & $0.55 \pm 0.14$ & 0.001 \\
\hline
\end{tabular}


The diagnostic predictability of cord alkaline phosphatase and albumin are shown in table 3 and figures $1 \mathrm{a}$ and $\mathrm{b}$.

Table (3): Diagnostic predictability of cord alkaline phosphatase (U/L) and cord albumin (g/dl) for diagnosis jaundice.

\begin{tabular}{|l|c|c|c|c|c|c|c|c|}
\hline \multicolumn{1}{|c|}{$\begin{array}{c}\text { Diagnosis } \\
\text { jaundice }\end{array}$} & AUC & $\begin{array}{c}\text { Cut } \\
\text { off } \\
\text { value }\end{array}$ & $\begin{array}{c}\text { P } \\
\text { value }\end{array}$ & Sensitivity & Specificity & PPV & NPV & $\begin{array}{c}\text { 95\% } \\
\text { CI }\end{array}$ \\
\hline $\begin{array}{l}\text { Cord } \\
\text { Alkaline } \\
\text { Phosphatase }\end{array}$ & 0.965 & $>315$ & 0.0001 & 95.0 & 100.0 & 100.0 & 93.0 & $\begin{array}{c}0.920- \\
1.00\end{array}$ \\
\hline $\begin{array}{l}\text { Cord } \\
\text { albumin }\end{array}$ & 0.983 & $<2.82$ & 0.0001 & 96.0 & 1.00 & 1.00 & 95.0 & $\begin{array}{c}.961- \\
1.00\end{array}$ \\
\hline $\begin{array}{l}\text { Need } \\
\text { phototherapy }\end{array}$ & 1.00 & $>315$ & 0.0001 & 100.00 & 100.00 & 100.00 & 100.00 & 1.00 \\
\hline $\begin{array}{l}\text { Cord } \\
\text { Alkaline } \\
\text { Phosphatase }\end{array}$ & 0.0001 & $<2.82$ & 1.00 & 100.00 & 100.00 & 100.00 & 100.00 & $\begin{array}{c}1.00- \\
0.0001\end{array}$ \\
\hline $\begin{array}{l}\text { Cord } \\
\text { albumin }\end{array}$ & & & & & & \\
\hline
\end{tabular}

AUC: area under curve PPV: positive predicted value NPV: negative predicted value CI: Confidence Interval

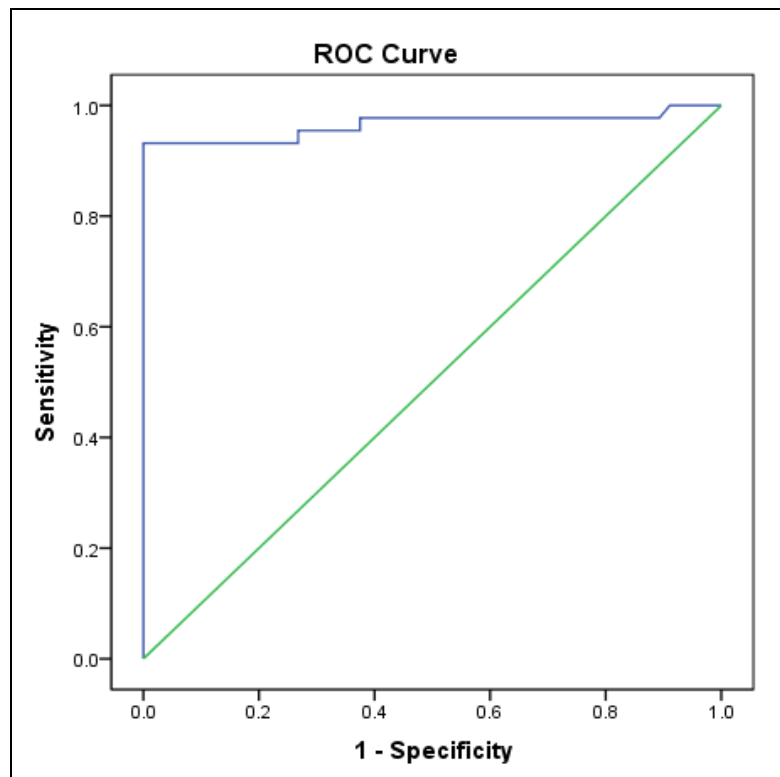

Figure 1(a): Roc curve of cord Alkaline Phosphatase (U/L) for diagnosis jaundice.

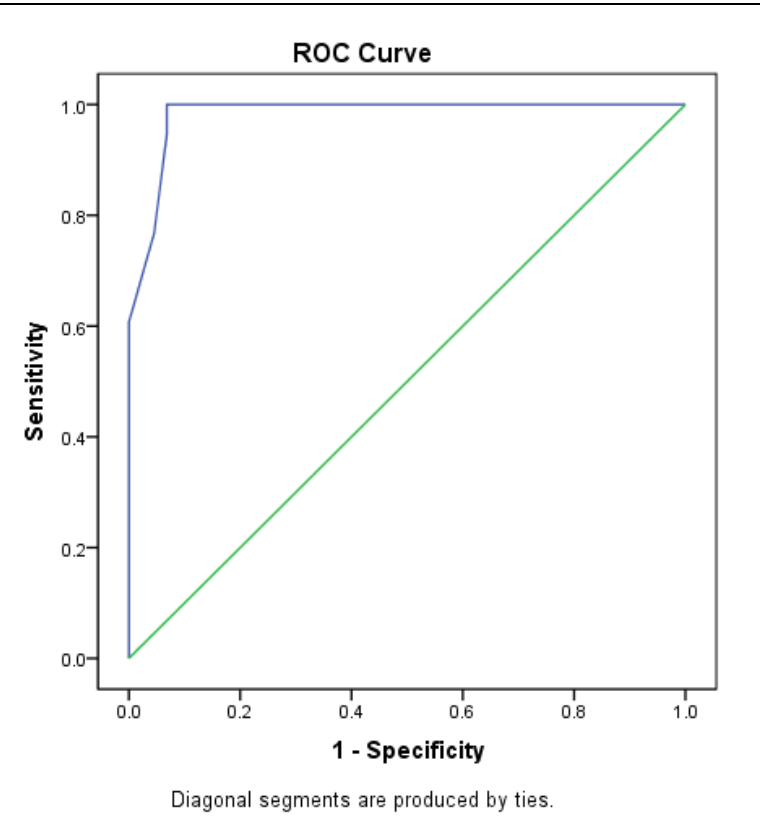

Figure 1(b): Roc curve of cord albumin (g/dl) for diagnosis jaundice.

The correlation between both cord alkaline phosphate and cord albumin and other basic clinical data is shown in table 4. 
Table (4): Correlation between both cord alkaline phosphate and cord albumin and other basic clinical and laboratory data.

\begin{tabular}{|c|c|c|c|}
\hline & & $\begin{array}{c}\text { Cord Alkaline Phosphatase } \\
\text { (ULL) }\end{array}$ & $\begin{array}{c}\text { Cord Albumin } \\
(\mathrm{g} / \mathrm{dl})\end{array}$ \\
\hline \multirow{2}{*}{ Cord Albumin } & $\mathrm{r}$ & -0.803 & ----- \\
\hline & P-value & 0.0001 & ---- \\
\hline \multirow{2}{*}{ Birth Wt. (Kg) } & $\mathrm{r}$ & -0.062 & 0.008 \\
\hline & P-value & 0.543 & 0.934 \\
\hline \multirow{2}{*}{ GA in weeks } & $\mathrm{r}$ & -0.025 & 0.071 \\
\hline & P-value & 0.806 & 0.481 \\
\hline \multirow{2}{*}{ Age of Onset } & $\mathrm{r}$ & -0.420 & 0.031 \\
\hline & P-value & 0.005 & 0.841 \\
\hline \multirow{2}{*}{ Apgar 1min } & $\mathrm{r}$ & -0.100 & 0.083 \\
\hline & P-value & 0.324 & 0.414 \\
\hline \multirow{2}{*}{ Apgar 5min } & $\mathrm{r}$ & -0.179 & 0.115 \\
\hline & P-value & 0.075 & 0.255 \\
\hline \multirow{2}{*}{$\mathrm{Hb}$} & $\mathrm{r}$ & 0.145 & -0.168 \\
\hline & P-value & 0.149 & 0.094 \\
\hline \multirow{2}{*}{ RETICS } & $\mathrm{r}$ & 0.298 & -0.310 \\
\hline & P-value & 0.003 & 0.002 \\
\hline \multirow{2}{*}{ fetal Rh } & $\mathrm{r}$ & 0.072 & -0.134 \\
\hline & P-value & 0.478 & 0.182 \\
\hline \multirow{2}{*}{ I/T Ratio } & $\mathrm{r}$ & 0.180 & 0.022 \\
\hline & P-value & 0.226 & 0.885 \\
\hline \multirow{2}{*}{ Admission Bilirubin } & $\mathrm{r}$ & -0.407 & -0.168 \\
\hline & P-value & 0.008 & 0.295 \\
\hline \multirow[t]{2}{*}{ D1 Total Bilirubin } & $\mathrm{r}$ & 0.702 & $-0.657^{* *}$ \\
\hline & P-value & 0.000 & 0.000 \\
\hline \multirow[t]{2}{*}{ D1 Direct Bilirubin } & $\mathrm{r}$ & -0.218 & 0.024 \\
\hline & P-value & 0.029 & 0.809 \\
\hline \multirow[t]{2}{*}{ D3 Total Bilirubin } & $\mathrm{r}$ & 0.639 & -0.820 \\
\hline & P-value & 0.000 & 0.000 \\
\hline \multirow[t]{2}{*}{ D3 Direct Bilirubin } & $\mathrm{r}$ & -0.247 & -0.482 \\
\hline & P-value & 0.013 & 0.000 \\
\hline \multirow[t]{2}{*}{ D4 Total Bilirubin } & $\mathrm{r}$ & 0.812 & 0.339 \\
\hline & P-value & 0.014 & 0.411 \\
\hline \multirow[t]{2}{*}{ D4 Direct Bilirubin } & $\mathrm{r}$ & -0.487 & 0.087 \\
\hline & P-value & 0.221 & 0.837 \\
\hline \multirow[t]{2}{*}{ D5 Total Bilirubin } & $\mathrm{r}$ & 0.636 & -0.909 \\
\hline & P-value & 0.001 & 0.000 \\
\hline \multirow[t]{2}{*}{ D5 Direct Bilirubin } & $\mathrm{r}$ & -0.364 & -0.670 \\
\hline & P-value & 0.001 & 0.000 \\
\hline \multirow[t]{2}{*}{ D6 Total Bilirubin } & $\mathrm{r}$ & 0.029 & -0.250 \\
\hline & P-value & 0.869 & 0.155 \\
\hline \multirow[t]{2}{*}{ D6 Direct Bilirubin } & $\mathrm{r}$ & 0.124 & 0.130 \\
\hline & P-value & 0.483 & 0.464 \\
\hline \multirow[t]{2}{*}{ D7 Total Bilirubin } & $\mathrm{r}$ & 0.072 & -0.015 \\
\hline & P-value & 0.725 & 0.944 \\
\hline \multirow[t]{2}{*}{ D7 Direct Bilirubin } & $\mathrm{r}$ & -0.234 & 0.154 \\
\hline & P-value & 0.250 & 0.452 \\
\hline
\end{tabular}

$\mathrm{r}=$ Correlation coefficient 


\section{DISCUSSION}

In the current study, there was no significant difference between the two groups regarding birth weight, sex, mode of delivery, gestational age, APGAR score at 1- and 5-min, and jaundiced previous sibling. The maternal data which included maternal age, multiple pregnancy, premature rupture of membranes (PROM), consanguinity, and maternal medications showed insignificant differences between the no jaundice group and jaundice group. In agreement with the previous results Ahmadpour-

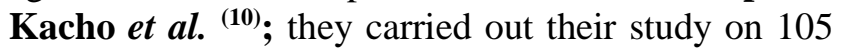
cases who were followed-up. Three cases were lost during the study. The remaining 102 cases consisted of $50(49 \%)$ males and $52(51 \%)$ females. Ninety-eight (96\%) infants were born by cesarean section and 4 (4\%) by vaginal delivery. Apgar scores were normal (9-10) at birth in all cases. The mean gestational age was 38.7 weeks and the mean birth weight was 3649.59 grams.

The incidence of clinical jaundice during follow-up was $47 \%$. In $39.2 \%$, bilirubin reached a peak of $\leq 10 \mathrm{mg} / \mathrm{dL}$. The rate of need for treatment was 9.8\% (10 cases), of which 5 cases were ABO incompatible, one case $\mathrm{Rh}$ incompatible, 2 cases G6PD deficient and in 2 cases the cause of jaundice remained unknown. Hematocrit levels and reticulocyte count were in normal range and Coombs test was negative in these cases. None of the neonates needed exchange transfusion. There was no difference between groups with regard to gestational age, birth weight and Apgar scores, but the comparison of cord blood alkaline phosphates levels revealed a significant difference between the two groups $(\mathrm{P}=0.041)^{(\mathbf{1 1})}$.

In terms of the mode of delivery, this study showed no difference between the two groups. This is in agreement with studies carried out by Rostami $\boldsymbol{e t}$ al. ${ }^{(12)}$. Also, Taks et al. ${ }^{(13)}$ found similar results but previously a study carried out by Awasthi and Rehman ${ }^{(14)}$ had reported that peak serum bilirubin was significantly higher in neonates delivered vaginally. There was no difference between the two groups in the present study in the gestational age and this is in contrast to the study carried out by Watchko (11) that found that neonatal hyperbilirubinemia occurs less commonly with increasing gestational age. The study carried out by Mutlu et al. (15) found a nonsignificant difference in the mode of feeding. Our study was not in agreement with Gartner ${ }^{(16)}$ who stated that late-onset, prolonged neonatal jaundice was more frequent in breast-fed infants than in artificially fed infants, and the association of breast-feeding with prolonged and exaggerated physiological jaundice of the newborn was considered a regular and frequently occurring phenomenon, with an incidence more than two thirds of all breast-fed infants.

In the present study, there was a highly significant difference between the two groups in the cord ALP level. Also, our results showed that cord alkaline phosphatase was significantly higher in jaundice group than no jaundice group. The diagnostic predictability of cord alkaline phosphatase (U/L) for diagnosis jaundice; the area under the curve was 0.965 , at the cut off value of alkaline phosphatase more than 315 (U/L) the sensitivity of diagnosis of jaundice was $95.0 \%$, the specificity was $100.0 \%$, PPV was $100.0 \%$ and the NPV was $93.0 \%$. This is consistent with Ahmadpour-Kacho et al. ${ }^{\left({ }^{(10)}\right.}$ study, in which the comparison of cord blood alkaline phosphates levels between non-jaundiced group and jaundiced newborns in whom bilirubin level had reached $\leq 10 \mathrm{mg} / \mathrm{dL}$, revealed a significant difference. Also, in agreement with our ROC curve analysis data, El-Amin et al. ${ }^{\left({ }^{17)}\right)}$ shows that cord ALP cut-off value more than $145 \mathrm{IU} / \mathrm{l}$ has a good predictive value for newborns who developed significant neonatal hyperbilirubinemia with a sensitivity of $72 \%$ and a specificity of $85.71 \%$. This is similar to the study of Ahmadpour-Kacho et al. ${ }^{(10)}$ who reported a cord blood ALP level of more than $314 \mu / 1$ to have a sensitivity of $80 \%$ and a specificity of $63 \%$ in predicting the risk of neonatal hyperbilirubinemia requiring treatment.

In our study the cord albumin showed a highly significant decrease in cord albumin in jaundice group more than the no jaundice. The diagnostic predictability of cord albumin $(\mathrm{g} / \mathrm{dl})$ for diagnosis jaundice; the area under the curve was 0.983 , at the cut off value of cord albumin $(\mathrm{g} / \mathrm{dl})$ less than $2.82(\mathrm{~g} / \mathrm{dl})$ the sensitivity of diagnosis of jaundice was $96.0 \%$, the specificity was $100.0 \%$, PPV was $100.0 \%$ and the NPV was 95.0\%. In agreement with our study Awad et al. ${ }^{(18)}$ found that cord blood albumin in jaundiced cases was statistically significantly lower than nonjaundiced cases and our data clearly demonstrated that there was negative significant correlation between cord blood albumin and total serum bilirubin level. This means that the lower the cord serum albumin levels the more was the chances of newborns developing hyperbilirubinemia. But there was no significant difference as regard to hemoglobin, hematocrit, reticulocyte count, PLT and TLC. This was in agreement with studies done by Reshad $\boldsymbol{e t} \boldsymbol{a l}$. ${ }^{(19)}$, Alalfy $\boldsymbol{e t} \boldsymbol{a l} .{ }^{(20)}$ as they concluded that there is significant correlation between cord serum albumin level and neonatal hyperbilirubinemia in healthy fullterm neonates $>2.5 \mathrm{~kg}$ birth weight and that serum albumin level taken from the blood of the umbilical cord is an effective way to predict neonatal hyperbilirubinemia in term healthy infants. The present study is in correlation with Gartner ${ }^{(16)}$ who found that neonates with umbilical cord blood albumin level more than $3.3 \mathrm{gm} / \mathrm{dl}$ can be safely discharged early whereas neonates with albumin levels $<3.3$ $\mathrm{gm} / \mathrm{dl}$ will need a close follow up to check for development of jaundice.

While analyzing the diagnostic predictability of cord serum albumin levels for neonatal 
hyperbilirubinemia in our study, the sensitivity was $(86 \%)$ and the specificity was $(80 \%)$. The positive predictive value was $(81 \%)$ and the negative predictive value was $(85 \%)$. The total bilirubin at day 1 showed a significant increase in jaundice more than nonjaundice, and at $3^{\text {rd }}$ and $5^{\text {th }}$ day the level of total bilirubin was significantly higher in jaundice group more than no jaundice. The level of direct bilirubin shows insignificant difference between no jaundice and jaundice group at the $1^{\text {st }}$ day, while at $3^{\text {rd }}$ and $5^{\text {th }}$ day it was found that the direct bilirubin was significantly higher in jaundice more than no jaundice group. Gaurav ${ }^{(21)}$ reported that the sensitivity of cord albumin to detect hyperbilirubinemia in newborn was $(71.8 \%)$, while specificity was $(65.1 \%)$. The positive predictive value was $(38.9 \%)$ and the negative predictive value was $(88.2 \%)$. The accuracy rate was $(67.3 \%)$ and the area under the ROC was $(0.684)$. Pahuja et al. ${ }^{(22)}$ noted that predictive value of cord albumin for development of neonatal hyperbilirubinemia was $75 \%$ which implies a fair predictive value of the criteria with $61.3 \%$ sensitive and $76.8 \%$ specific, which is in correlation with the present study. A study by Nahar et al. ${ }^{(23)}$ showed cord bilirubin level $>2.5 \mathrm{mg} / \mathrm{dl}$ had a sensitivity of $77 \%$, specificity of $98.6 \%$ with negative predictive value of $96 \%$, which is in correlation with the present study.

\section{CONCLUSION}

We can conclude that both cord albumin levels and cord blood alkaline phosphatase in a healthy term neonate can predict neonatal hyperbilirubinemia. It helps to determine the neonates who are at a higher risk of developing jaundice. A value less than 2.8 $\mathrm{gm} / \mathrm{dl}$ for cord albumin and more than $315 \mathrm{U} / \mathrm{L}$ for alkaline phosphatase, have been found to be more associated with clinical icterus. Hence routine determination of cord albumin along with alkaline phosphatase can be implemented to keep track of atrisk neonates.

\section{REFERENCE}

1. Kalakheti B, Singh R, Bhatta $N$ et al. (2009): Risk of neonatal hyperbilirubinemia in babies born to 'O'positive mothers: A prospective cohort study. KUMJ., 7(1):11-5.

2. Farhat R, Rajab M (2011): Length of postnatal hospital stay in healthy newborns and re-hospitalization following early discharge. North Am J Med Sci., 3(3):146-53.

3. Ip S, Chung M, Kulig J et al. (2004): American Academy of Pediatrics Subcommittee on Hyperbilirubinemia. An evidence-based review of important issues concerning neonatal hyperbilirubinemia. Pediatrics, 114(1):130-53.

4. Johnson L, Bhutani V, Karp K et al. (2009): Clinical report from the pilot USA Kernicterus Registry (1992 to 2004). J. Perinatol., 29(1):25-45.

5. Taksande A, Vilhekar K, Jain M et al. (2005): Prediction of the development of neonatal hyperbilirubinemia by increased umbilical cord blood bilirubin. Ind Medica., 9(1):59.

6. Hegde $P$ (2013): Cord serum bilirubin and albumin in neonatal hyperbilirubinemia. Int J Int Sci., 2(2):39-42.

7. Chaudhry E, Naveed A, Rahim A et al. (2016): Decreased Cord Blood Albumin: A Predictor of Neonatal Jaundice. JIIMC., 11(4):149-52.

8. Ahire N, Sonawane R, Gaikwad R et al. (2016): Study of correlation of cord blood bilirubin with neonatal hyperbilirubinemia. MVP Journal of Medical Science, 3(1):60-6.

9. Fluss R, Faraggi D, Reiser B (2005): Estimation of the Youden Index and its associated cutoff point. Biometrical Journal, 47(4):458-72.

10. Ahmadpour-Kacho M, Pasha $Y$, Haghshenas $M$ et al. (2015): Cord blood alkaline phosphatase as an indicator of neonatal jaundice. IRAN J Pediatr., 25(5): 32-36.

11. Watchko J (2006): Hyperbilirubinemia and bilirubin toxicity in the late preterm infant. Clinics in Perinatology, 33(4):839-52.

12. Rostami N, Mehrabi Y, Asadzadeh F (2005): Identifying the newborns at risk for developing significant hyperbilirubinemia by measuring cord bilirubin levels. Sci Inform Datebase , 9:365-72.

13. Taks A, Vilhekar K, Jain M et al. (2005): Prediction of the development of neonatal hyperbilirubinemia by increased umbilical cord blood bilirubin. Curr Pediatr Res., 9:5-9.

14. Awasthi R, Rehman S (2009): Correlation between cord blood bilirubin level and incidence of hyperbilirubinemia in term newborns. Paediatr Indones., 49:349-354.

15. Mutlu M, Çayır Y, Aslan Y (2014): Urinary tract infections in neonates with jaundice in their first two weeks of life. Sci World J Pediatr., 10(2):164-9.

16. Gartner L (2001): Breastfeeding and jaundice. J Perinatol., 21(1):25-9.

17. El-Amin D, Ahmed Y, Hashim A et al. (2020): Evaluation of cord blood alkaline phosphatase levels as an indicator of neonatal jaundice. AMJ., 18(2):112-116.

18. Awad H, Hasan M, Khaleil G (2020): Cord Blood Albumin as a Predictor of Neonatal Jaundice. EJHM., 81(1):1217-25.

19. Reshad M, Ravichander B, Raghuraman T (2016): A study of cord blood albumin as a predictor of significant neonatal hyperbilirubinemia in term and preterm neonates. Int J Res Med Sci., 4(3):887-90.

20. Alalfy M, El Lithy A, EzzEldin Z et al. (2018): Role of bilirubin and albumin in cord blood as predictors for neonatal hyperbilirubinemia. J Gynecol Res., 4(2):208-212.

21. Gaurav A (2017): Cord blood albumin as a predictor of neonatal hyperbilirubinemia in healthy neonates Curr Pediatr Res., 21(2):216-20.

22. Pahuja M, Dhawan S, Chaudhary S (2016): Correlation of cord blood bilirubin and neonatal hyperbilirubinemia in healthy newborns. Int J Contemp Pediatr., 3(926): e30.

23. Nahar Z, Shahidullah M, Mannan A et al. (2009): The value of umbilical cord blood bilirubin measurement in predicting the development of significant hyperbilirubinemia in healthy newborn. Bangladesh J Child Health, 33(2):50-4. 